\title{
NOVO ENSINO MÉDIO: DERIVA DE SENTIDOS EM UMA PROPAGANDA TELEVISIVA DO GOVERNO FEDERAL
}

\author{
New High School: Nueva Enseñanza Secundaria: \\ Derive of Senses on a TV Advertisement desviación de sentidos en una \\ by the Federal Government propaganda televisiva del Gobierno Federal
}

\author{
Carlos Fabiano de Souza* \\ Instituto Federal de Educação, Ciência e Tecnologia Fluminense, Cabo Frio, RJ, Brasil
}

\begin{abstract}
Resumo: Este artigo, à luz de um viés discursivo, parte da materialidade linguística presente em sete quadros recortados de um vídeo de propaganda televisiva do Novo Ensino Médio pelo Governo Federal para investigar a deriva de sentidos postos em circulação acerca da enunciabilidade inscrita nos discursos sobre trabalho e formação integral. A análise ancora-se na sociologia do discurso do Círculo de Bakhtin, tomando por base especialmente a concepção de material ideológico sígnico (VOLÓCHINOV, 2017 [1929; 1930]), e na AD de base enunciativa, a partir de fundamentos da semântica global proposta por Maingueneau (2008). Os resultados reforçam o efeito de silenciamento (ORLANDI, 2007) que atravessa essa medida do Governo, na qual a educação em nível médio tende a não contemplar a dimensão humana (integral), não concebendo o trabalho em sua dimensão educativa, ontológica, como constitutivo do homem, por meio do qual o indivíduo dá sentido ao mundo em que vive.
\end{abstract}

Palavras-chave: Trabalho. Formação integral. Ensino médio. Sociologia do discurso. Análise do discurso.

Abstract: In the light of a discursive perspective, this study focuses on the linguistic materiality depicted in seven frames excerpted from a TV advertisement video of the New High School by the Federal Government, aiming to investigate the derive of senses that circulate on the inscribed enunciability in discourses about work and integral education. Our analysis finds support in the sociology of discourse presented by the Bakhtin Circle, specifically the conception of ideological sign (VOLÓCHINOV, 2017 $[1929,1930])$ and the Enunciative Discourse Analysis based on the principles of global semantics brought by Maingueneau (2008). The results reinforce the effect of silence (ORLANDI, 2007) that is in this governmental measure. The high school education tends not to contemplate the (integral) human dimension, as well as it does not take in consideration the work, a constitutive matter of men, in its educative, ontological dimension, since it is through it the individual gives sense to his world.

Keywords: Work. Integral education. High School. Sociology of discourse. Discourse Analysis.

Resumen: Bajo la luz de un sesgo discursivo, este artículo parte de la materialidad lingüística presente en siete cuadros cortados de un video de propaganda televisiva de la Nueva Enseñanza Secundaria por el Gobierno Federal para investigar la desviación de sentidos puestos en circulación acerca de los enunciados inscritos en los discursos sobre trabajo y formación integral. El análisis se basa en la sociología del discurso del Círculo de Bajtín, tomando-se por base especialmente la concepción de material ideológico sígnico (VOLÓCHINOV, 2017 [1929; 1930]), y en el AD de base enunciativo, desde fundamentos da semántica global propuesta por Maingueneau (2008). Los resultados refuerzan el efecto de silenciamiento

* Doutorando no Programa de Pós-graduação em Estudos de Linguagem da Universidade Federal Fluminense (UFF). Professor do Instituto Federal de Educação, Ciência e Tecnologia Fluminense (IFFluminense) Campus Cabo Frio, RJ. ORCID: https://orcid.org/0000-0001-6101-9950. E-mail: carlosfabiano.teacher@gmail.com. 
(ORLANDI, 2007) que atraviesa esa medida del Gobierno, en que la educación de nivel secundario tiende a no contemplar la dimensión humana (integral), no concibiendo el trabajo en su dimensión educativa, ontológica, como constitutivo del hombre, por medio del cual el individuo da sentido al mundo en el que vive.

Palabras clave: Trabajo. Formación integral. Enseñanza secundaria. Sociología del discurso. Análisis del discurso.

\section{INTRODUÇÃOO}

Em face de um cenário de mudanças, este texto focaliza a Medida Provisória $n^{\circ}$ 746, de 22 de setembro de 2016 (doravante MP) ${ }^{1}$, cujo propósito é instituir a política de fomento à implementação de Escolas de Ensino Médio (doravante EM) em tempo integral, alterando, assim, a Lei $\mathrm{n}^{\mathrm{o}}$ 9.394, de 20 de dezembro de 1996, que estabelece as diretrizes e bases da educação nacional.

Popularmente conhecida como a Reforma no/do EM, o texto da MP tem sido alvo de amplas críticas, particularmente por não ter sido colocada em discussão entre os principais interessados, quais sejam: profissionais especializados da área de educação e demais membros da sociedade civil.

Embora haja um tácito reconhecimento de que reformas são necessárias, presumese que ela contribui para o aumento da desigualdade social, atacando sobremaneira o estado democrático de direito. Uma medida dessa natureza e, principalmente, da maneira como foi (im/pro)posta, pode significar um retrocesso no que se refere à construção de uma sociedade mais justa, com mais equidade.

Objetivamente, à luz de um viés discursivo, este artigo investiga a deriva de sentidos postos em circulação por meio de enunciados sobre trabalho e formação integral, recuperados a partir da materialidade linguística presente em sete quadros recortados de um material audiovisual, televisionado, de propaganda do "Novo" EM pelo Governo Federal.

Nosso enfoque parte da concepção desse material formado por um conjunto de imagens com legendas, capturadas em quadros, a partir de um vídeo de 30 segundos, entendido, na perspectiva bakhtiniana, como um material ideológico sígnico. Ou seja, um todo dotado de significação por meio do qual se torna possível a deriva de sentidos, que são produzidos por enunciados tecidos no fio discursivo, refletindo ou refratando a realidade que se encontra fora de seus limites (VOLÓCHINOV, 2017 [1929; 1930]).

Esse recorte é tomado em diálogo com o texto da MP, duas respostas postadas na seção Dúvidas no portal do Ministério da Educação (MEC) acerca do que se pretende com o "Novo" EM, e a Justificativa 18 - enviada ao Congresso Nacional pelo Governo (CÂMARA DOS DEPUTADOS, 2016).

\footnotetext{
${ }^{1}$ Esse texto também altera a Lei ${ }^{\circ} 11.494$ de 20 de junho de 2007, destinada a regulamentar o Fundo de Manutenção e Desenvolvimento da Educação Básica e de Valorização dos Profissionais da Educação, trazendo a reboque outras providências (BRASIL, 2016).
} 
A análise ancora-se ainda na sociologia do discurso do Círculo de Bakhtin e na Análise do Discurso (AD) de base enunciativa, alimentando-se especificamente dos fundamentos da semântica global (MAINGUENEAU, 2008). Esta considera que todas as dimensões do funcionamento discursivo se encontram imbricadas, operando como uma rede de restrições.

Os resultados apresentados buscam evidenciar o efeito de silenciamento (ORLANDI, 2007) que atravessa essa medida do Governo, trazendo a lume a produtividade dessas concepções teóricas no que tange a analisar enunciados que circulam em vídeos postados na Internet.

Para tanto, concebemos os enunciados que aparecem verbalizados no vídeo de forma integrada. Isto é, não apenas apreendendo o aspecto discursivo que os atravessa sob um único plano, mas levando-se em conta, sobretudo, todos os seus elementos "ao mesmo tempo, tanto na ordem do enunciado quanto na da enunciação" (MAINGUENEAU, 2008, p. 75).

Apesar de nossa análise se pautar no EM, em tempo integral, a ser implementado na educação básica (doravante EB) pública em todo território nacional, levamos em conta neste trabalho essa política de fomento em um constante contraponto com o EM Técnico Integrado que se realiza de forma integral em diversas escolas que fazem parte da Rede Federal Tecnológica (RFT). Isso se deve em virtude de se considerar ser este um contexto bastante produtivo de observação de práticas educacionais na contemporaneidade, onde têm ocorrido debates sobre os avanços e desafios da oferta de cursos com foco nesse tipo de formação.

Destaca-se, ainda, que os resultados sinalizam que, por meio da MP, dá-se a ver que a educação em nível médio tende a não contemplar a dimensão humana, integral, não concebendo o trabalho, desse modo, em sua dimensão educativa, ontológica, constitutivo do homem, por meio do qual o indivíduo dá sentido ao mundo em que vive.

A seguir, o texto se organiza em três seções. Na primeira, dividida em duas subseções, trazemos ao debate uma concepção particular de trabalho e alguns desafios impostos pelo processo de integralização envolvido na formação dos estudantes.

$\mathrm{Na}$ segunda parte, a partir de breves considerações sobre o que se entende por EM, apresentamos a análise, evidenciando a deriva de sentidos postos em circulação por meio de enunciados sobre trabalho e formação integral em um vídeo de propaganda governamental. Por fim, trazemos as considerações finais, seguidas das referências.

\section{A RELAÇÃO TRABALHO E FORMAÇÃO INTEGRAL}

Parece existir um aspecto importante a mencionar quando se trata de colocar em palavras o trabalho: sua intrínseca relação com o homem. Além disso, costuma-se tecer considerações acerca de como o trabalho atua na relação homem/natureza, desde a sua origem, transformando-a e, assim, fazendo sua história. Nesse processo, “[...] como o modo de vida do homem não é garantido pela natureza, pois que é o próprio homem que o produz, à medida que se torna homem, aprende, cada vez mais, a se humanizar" (SILVEIRA, 2010, p. 89). 
Em outras palavras, é a partir dessa relação, em um movimento de humanização, um processo educativo mediado pelo trabalho, que buscamos melhor compreender que contornos essa atividade humana ganha no âmbito educacional na sociedade capitalista de nosso tempo.

Estamos, por assim dizer, em um contexto de práticas neoliberais que tendem a ditar as regras do jogo, de modo que "os novos paradigmas tecnológicos sustentam novos modos de organização do trabalho, novos mecanismos de dominação e exploração da classe trabalhadora" (SILVEIRA, 2010, p. 86).

Entretanto, antes de melhor compreender os sentidos atribuídos ao trabalho na perspectiva de nosso tempo, enfocando especialmente o contexto brasileiro, ressalta-se que a acepção primeira de trabalho de que trata Silveira (2010) está sustentada no pensamento marxista (MARX, 2016 [1890]). Cabe ainda pontuar que, apesar de essa relação não tão trivial, a tentativa de discorrer sobre o trabalho não é algo simples. Prova disso é o fato de que diferentes áreas do saber significam o trabalho à luz de suas especificidades e diferentes naturezas epistemológicas.

Tendo em vista essa problemática, nos dedicamos agora a fazer breves ponderações acerca da complexidade relacionada à apreensão do termo trabalho, caminhando em direção aos sentidos postos em circulação quando se toma o contexto da formação integral, especialmente em relação ao EM.

\subsection{TRABALHO: UM CONCEITO COMPLEXO, AMBÍGUO E DISPUTADO}

Para Tersac e Maggi (2004, p. 80), "o trabalho é um conceito complexo não só porque suas práticas variam de uma situação a outra, mas também porque seu sentido varia ao longo do tempo e de uma sociedade para outra".

Ao analisar o trabalho sob a lente da fluidez da modernidade, Bauman (2001) evidencia o papel que ele adquiriu elevando-se ao posto de principal valor dos tempos modernos, tal que "[...] ao trabalho foram atribuídas muitas virtudes e efeitos benéficos, como, por exemplo, o aumento da riqueza e a [suposta] eliminação da miséria [...]" (BAUMAN, 2001, p. 172).

Ademais, podemos dizer que o termo é um conceito “[...] ambíguo e disputado, indicando diferentes atividades em diferentes sociedades e contextos históricos" (OUTHWAITE; BOTTOMORE, 1996, p. 773), de modo que para muitas pessoas ele se converte em sinônimo de emprego remunerado.

Atribuir ao termo em destaque o sentido de emprego é uma coloração semântica própria do neoliberalismo, permitindo, assim, que o conceito transite em meio à fluidez dos tempos modernos proposta por Bauman, em que as experiências fragmentadas tendem a implicar diferentes percepções dessa atividade, visto que não se tem mais a garantia da estabilidade, do controle da ordem.

Conforme Bezerra (2013), ao relacionarmos trabalho e educação é fundamental compreender como ele adquire uma significação própria na sociedade capitalista, na qual se tem naturalizado a ideia de que sua dimensão ontológica está restrita a uma única face de sua dimensão histórica, qual seja: o trabalho como emprego. Nesse sentido, reduz-se o seu conceito à relação de compra e venda da força de trabalho na forma de um contrato. 
É importante destacar que o pensamento marxista coloca em evidência as relações estabelecidas entre capital/trabalho, presentes em todos os países do mundo na contemporaneidade, apontando que a superação desse quadro, que leva a uma alienação (causa da propriedade privada e produto da economia política submetido pela burguesia), dificulta a emancipação político-social e humana do trabalhador (SILVEIRA, 2010).

No cerne dessa questão está o fato de que existe uma teia que enreda o trabalhador, na qual "a utilização da força de trabalho é o próprio trabalho" (MARX, 2016 [1890], p. 211) e, com o intuito de superar essa condição, só será possível a ele alcançar sua emancipação quando este tiver condições de "entender a relação entre si, o trabalho e o produto do seu trabalho [...] [dotado de uma consciência crítica, a fim de] romper com a lógica da produção burguesa" (SILVEIRA, 2010, p. 92). "Em outros termos, significa [dizer] que a emancipação humana se faz na totalidade das relações sociais onde a vida é produzida" (CIAVATTA, 2012, p. 85).

Partindo da complexidade envolvida na maneira pela qual se almeja tomar o conceito de trabalho, e situando-o no amplo escopo capitalista neoliberal, passamos à subseção seguinte, na qual buscamos compreender em que consiste, de fato, a relação trabalho e formação integral no contexto de fomento do "Novo" EM no Brasil.

\subsection{FORMAÇÃO INTEGRAL: CONCEPÇÃO E DESAFIOS}

Nesta subseção, objetivamos problematizar a questão da formação integral em sua relação com o conceito de trabalho, em sua dimensão educativa e ontológica.

Esse direcionamento se dá em um constante contraponto com a perspectiva do percurso formativo integral que se realiza no âmbito do Ensino Técnico integrado ao EM, em escolas da RFT, como os Institutos Federais (IFs).

Grosso modo, entendemos por integral, no quadro da proposta do Governo para o EM, o tempo de estudo que se realiza ao longo de dois turnos diários completos (manhã e tarde), durante o qual o estudante tende a ocupar-se de atividades educativas dentro da escola, com acesso a pelo menos sete horas de aprendizagem por dia.

Esse conceito é comumente confundido com a perspectiva da formação integral que nos interessa neste trabalho, que abrange uma concepção mais ampla, entendida como a formação humana do cidadão, em todas as suas dimensões.

Isso leva em conta, a partir do que prevê a Lei de Diretrizes e Bases da Educação Nacional (LDBEN/1996), "o aprimoramento do educando como pessoa humana, incluindo a formação ética e o desenvolvimento da autonomia intelectual e do pensamento crítico" (BRASIL, 2000, p. 33), com vistas à formação cidadã para o mundo do trabalho.

Nessa perspectiva,

como formação humana, o que se busca é garantir ao adolescente, ao jovem e ao adulto trabalhador o direito a uma formação completa para a leitura do mundo e para a atuação como cidadão pertencente a um país, integrado dignamente à sua sociedade política. Formação que, neste sentido, supõe a compreensão das relações sociais subjacentes a todos os fenômenos (CIAVATTA, 2012, p. 85). 
Essas explicitações suscitam aspectos relevantes que cooperam para uma compreensão ampliada desse conceito, numa perspectiva de formação que considera o papel do cidadão como transformador, fomentador da promoção da justiça, do desenvolvimento sustentável, mirando à inclusão social.

No caso da formação humana integral a ser implementada no EM, em tempo integral, nas escolas públicas do Brasil, cabe dizer que um de seus grandes desafios se encontra atrelado ao descaso com que se tem tratado a EB em nosso país.

Esse descaso, tão disseminado em enunciados que circulam em nossa sociedade, tem como reflexo o sucateamento dos espaços públicos de ensino, com escolas superlotadas, sem estrutura física adequada, com professores desmotivados, por conta da falta de incentivo salarial e qualificação, só para citar alguns fatores. Somam-se a isso a carência de profissionais formados para dar conta de determinados componentes curriculares, como química, física e biologia, em especial, além da violência que tem assolado esses ambientes educativos.

Então, como manter os estudantes de escolas públicas brasileiras em tempo integral em espaços que apresentam esse quadro caótico? Para colocar em prática esse tipo de proposta bastaria deixar os nossos estudantes por cerca de sete horas, em dois turnos diários, em escolas que não têm condições mínimas de atender às necessidades desses estudantes, até mesmo em um único turno?

Se considerarmos o EM (na modalidade: integrado), em tempo integral nos IFs, escolas que têm sob sua responsabilidade também a EB, ainda assim há muitos desafios a serem superados. Primeiramente, podemos dizer que esses espaços apresentam inegavelmente uma melhor estrutura física se comparada ao quadro das demais escolas públicas espalhadas em todo o território nacional.

Em um segundo plano, destaca-se o forte investimento ${ }^{2}$ que as instituições federais têm recebido ao longo dos anos, mais especificamente se considerarmos os mandatos dos presidentes Lula e Dilma, por meio dos quais a RFT passou por uma grande expansão atingindo a marca de mais de 640 unidades em atividade no país.

Nesse contexto, destaca-se o investimento na qualificação profissional dos professores e demais servidores da Rede, além de relevante e maciço incremento em políticas com programas de mobilidade e intercâmbio acadêmico-científico para servidores e estudantes em instituições estrangeiras.

No entanto, muito se tem debatido acerca da carga horária dos currículos que compõem os eixos tecnológicos dos programas de ensino nos IFs. Essas discussões colocam em xeque a quantidade de componentes curriculares com os quais os estudantes têm que lidar na interface EB/educação profissional, pois ainda que eles fiquem na escola durante dois turnos diariamente para dar conta da grade curricular, muitos desses Institutos têm seus campi afastados dos grandes centros, tal que os estudantes chegam muito tarde a casa e têm que acordar muito cedo no dia seguinte para retornar à escola.

\footnotetext{
${ }^{2}$ Entretanto, a fim de melhor delinear o quadro em que se encontra a RFT nos dias de hoje, análises mais aprofundadas merecem ser desenvolvidas, levando em conta sobremaneira a atual conjuntura política sob a lente da crise econômica e política instaurada no Brasil.
} 
Esse é um fator que foi destacado por Silva (2011), em seu trabalho sobre Evasão escolar nos cursos técnicos integrados do IFBA Campus Eunápolis, no qual o pesquisador identificou que a pesada carga horária de aulas contribui para que o estudante abandone a escola. Esse número de aulas acaba se revertendo em excesso de atividades e tarefas avaliativas, implicando a reprovação dos estudantes em mais de uma disciplina.

Esse aspecto é caracterizado como fator externo à escola, pois ainda que a expansão tenha o papel de aproximar as escolas de grandes rincões, o processo de interiorização não consegue resolver a questão em sua plenitude, visto que um campus acaba atendendo a vários municípios ao mesmo tempo, com distâncias variadas em relação à escola.

Dessa maneira, essa dificuldade de locomoção do estudante entre o Instituto e sua moradia pode contribuir para o desgaste físico dos estudantes, interferindo essencialmente no processo educativo, o que pode, inclusive, servir para justificar o péssimo rendimento escolar de estudantes de classes sociais mais baixas que moram em área periférica, levando até mesmo à evasão escolar.

Ainda se referindo ao estudo de Silva (2011), o estudioso verificou que um dos fatores externos à instituição que tem levado os estudantes a evadir diz respeito às dificuldades com deslocamento. Essa dificuldade se manifesta pela própria distância, aspecto geográfico, ou pela situação econômico-financeira dos estudantes, um dos fatores também evidenciado.

Sabe-se que há cidades em que os estudantes têm o direito ao passe livre para se deslocar até a unidade de ensino. Entretanto, a baixa renda de alguns pais de estudantes do EM pode aumentar esse quadro de dificuldade, pois presume-se que há situações em que os estudantes têm que pagar a passagem, tornando-se um complicador na continuidade dos estudos, pois como nos adverte Silva (2011), em se tratando de evasão escolar nos Institutos, é importante

\footnotetext{
[...] analisar o dado Renda Familiar destes estudantes. [...] quantas pessoas nos dias de hoje têm dificuldades quando se trata do rendimento financeiro? Com os estudantes de Ensino Médio não é nada diferente. Os pais recebem baixos salários e, às vezes, não têm condições de comprar materiais e pagar passagem para seus filhos frequentar a escola, resultando em um típico conflito vivido pelos estudantes adultos [que não trabalham, em especial] (SILVA, 2011, p. 8-9).
}

Em face dessas considerações, apesar da carência de estudos sobre a questão da evasão escolar nessa modalidade de ensino no Brasil, é correto afirmar com Machado e Moreira (2012, p. 2) que "a ausência de estudos sobre o tema pode estar relacionada ao fato de que o processo de democratização da escola técnica de nível médio no Brasil apenas se iniciou". 
Entretanto, ainda que com todo aparato-tecnológico, com todo suporte oferecido aos estudantes por meio de políticas de assistência estudantil ${ }^{3}$, para que os estudantes permaneçam na escola, os pontos até aqui mencionados mostram que existem inúmeros fatores externos à instituição que dificultam a permanência do estudante na escola pública brasileira, mesmo naquelas que já operam em tempo integral como no caso das unidades da RFT.

Como se observa, manter o estudante em tempo integral na escola pública brasileira implica um esforço que demanda políticas efetivas que devem ir além da simples imposição de que as escolas devam cumprir com essa exigência, pois existem diversos fatores externos à escola envolvidos nesse processo.

Os IFs são escolas públicas reconhecidas pelo seu potencial na oferta de ensino público de qualidade, com o objetivo de "atender os estados e microrregiões se configurando como um processo real de democratização regional da educação técnica de nível médio e superior no nosso país" (BUENO, 2015, p. 22).

Se essas escolas públicas que gozam de certo investimento têm enfrentado dificuldades quanto à oferta da modalidade de ensino em tempo integral, o que esperar da tentativa de colocar em prática o EM nessa modalidade em escolas públicas localizadas em áreas periféricas, com comunidades em situação de vulnerabilidade social, para citar apenas uma dimensão da questão?

Na próxima seção, tratamos mais detidamente dos materiais e procedimentos de análise.

3 "NOVO" EM: DERIVA DE SENTIDOS EM PROPAGANDA TELEVISIVA DO GOVERNO FEDERAL

Para entender em que consiste o EM brasileiro, levamos em conta o que diz o texto da LDBEN (BRASIL, 1996), no qual se postula que ele se constitui na etapa final da EB, com duração mínima de três anos. No que toca a suas finalidades, os incisos de I a IV identificam seu papel em garantir que o estudante tenha condições de aprofundar os saberes construídos ao longo do ensino fundamental, permitindo, ainda, a continuidade dos estudos, para a inserção no mundo do trabalho e o exercício pleno da cidadania, afinando sua formação ética e o pensamento crítico a sua atuação político-social no mundo em que vive.

De acordo com os Parâmetros Curriculares Nacionais (PCNEM), o EM:

[...] É a etapa final de uma educação de caráter geral, afinada com a contemporaneidade, com a construção de competências básicas, que situem o educando como sujeito produtor de conhecimento e participante do mundo do trabalho, e com o desenvolvimento da pessoa, como 'sujeito em situação' - cidadão (BRASIL, 2000, p. 10).

\footnotetext{
${ }^{3}$ Os IFs contam com uma política de ações afirmativas que busca contribuir com a assistência estudantil, provendo os estudantes com programas de bolsas, auxílio alimentação, cooperando, assim, com a tentativa de diminuir com a evasão escolar, aumentando as condições dos estudantes de permanecerem na escola. Muitas dessas ações são implementadas por meio de Diretorias de Assuntos Estudantis.
} 
O aspecto da produção de conhecimento é enfatizado sobremaneira nos PCNEMs pautados que estão na LDBEN, na qual se assegura que a compreensão dos fundamentos científicos e tecnológicos esteja a serviço dos mais diversos arranjos produtivos locais, almejando a inclusão social nesse mundo permeado pela desigualdade, com um projeto pactuado com a construção de uma sociedade fundada na igualdade econômica, político e social.

Já o texto das Orientações Curriculares (OCEM) enfatiza, dentre outros aspectos, a necessidade de se investir nas "diferentes manifestações da linguagem - como a dança, o teatro, a música, a escultura e a pintura -, bem como valorizar a diversidade de ideias, culturas e formas de expressão" (BRASIL, 2006, p. 33), em diálogo com os diferentes campos do saber.

Essas ponderações também se aplicam ao EM integrado à educação profissional de nível técnico, englobando todos esses sentidos ao se enfatizar que:

\begin{abstract}
Nosso objetivo central não é formar um profissional para o mercado, mas sim um cidadão para o mundo do trabalho - um cidadão que tanto poderia ser um técnico quanto um filósofo, um escritor ou tudo isso. Significa superar o preconceito de classe de que um trabalhador não pode ser um intelectual, um artista. A música, tão cultivada em muitas de nossas escolas, deve ser incentivada e fazer parte da formação de nossos alunos, assim como as artes plásticas, o teatro e a literatura. Novas formas de inserção no mundo do trabalho e novas formas de organização produtiva como a economia solidária e o cooperativismo devem ser objeto de estudo [...] (PACHECO, 2011, p. 11).
\end{abstract}

Partindo dessas colocações preliminares, nossa proposta nesta seção é analisar os enunciados presentes em sete quadros recortados de um material audiovisual, televisionado, de propaganda do "Novo" EM, tomando-o como uma unidade que produz significados. Nossa hipótese é de que a partir dessa materialidade linguística é possível descrever a deriva de sentidos postos em circulação por meio de enunciados sobre trabalho e formação integral.

Nosso material de análise faz parte de um vídeo de 30 segundos, que se encontra disponibilizado no YouTube.com, tendo sido recortado em imagens, com legendas, capturadas em quadros. Temos, então, um material ideológico sígnico, dotado de significação, por meio do qual se torna possível o deslocamento de sentidos que são produzidos por enunciados tecidos no fio discursivo, refletindo ou refratando a realidade que se encontra fora de seus limites (VOLÓCHINOV, 2017 [1929; 1930]).

Ademais, considerando a semântica global (MAINGUENEAU, 2008), nossa proposta busca levar em conta todos os elementos envolvidos nesse material ideológico sígnico, no seio da produção e da circulação desse vídeo, pois todas as suas dimensões estão envolvidas e organizadas em um sistema de restrições, e só fazem sentido se tomadas no conjunto do funcionamento discursivo.

Para este procedimento de análise, mobilizamos as seguintes dimensões: (1) o vocabulário; (2) os temas; e (3) o estatuto do enunciador e do destinatário (MAINGUENEAU, 2008). Em outras palavras, nos interessa considerar os diferentes elementos que compõem a semântica discursiva desse material, compreendendo que 
o conjunto de elementos semânticos habitualmente usado nos discursos de uma dada época constitui a maneira de ver o mundo numa dada formação social. Esses elementos surgem a partir de outros discursos já constituídos, cristalizados e cujas condições de produção foram apagadas. [...] A semântica discursiva é o campo da determinação ideológica propriamente dita (FIORIN, 1998, p. 19).

E ainda que se opte por considerar um único plano na análise do campo semântico, "é a significância discursiva em seu conjunto que deve ser inicialmente visada [...] [, pois no âmbito desse conjunto está] um sistema que investe o discurso na multiplicidade de suas dimensões" (MAINGUENEAU, 2008, p. 76).

Ao tomar o vídeo de uma propaganda governamental como um objeto físico, sua transposição em material ideológico sígnico se dá tendo em vista que o objeto físico pode ser transformado em signo. E, assim sendo, ao recortar a materialidade linguística que atravessa o seu fio discursivo, tende-se a observar que os enunciados passam a refratar, a distorcer ou refletir uma realidade que vai além de seus limites, constituindo-se nessa interdiscursividade em uma arena de disputas, embates ideológicos, na qual o signo se transforma em palco da luta de classes.

É nessa perspectiva que se pode dizer que:

Os signos também são objetos únicos e materiais e [...] qualquer objeto da natureza, da tecnologia ou de consumo pode se tornar um signo. Neste caso, porém, ele irá adquirir uma significação que ultrapassa os limites da sua existência particular. O signo não é somente uma parte da realidade, mas também reflete e refrata uma outra realidade, sendo por isso mesmo capaz de distorcê-la, ser-lhe fiel, percebê-la de um ponto de vista específico e assim por diante (VOLÓCHINOV, 2017, [1929; 1930] p. 93).

Seu caráter ideológico, neste caso, diz respeito ao fato de que "onde há signo há também ideologia. Tudo o que é ideológico possui significação sígnica" (VOLÓCHINOV, 2017, [1929; 1930] p. 93).

A ideologia, dessa forma, é constitutiva da realidade e dela se constitui, tal que se pode afirmar que "não há um conhecimento neutro, pois ele sempre expressa o ponto de vista de uma classe a respeito da realidade. Todo conhecimento está comprometido com os interesses sociais" (FIORIN, 1998, p. 29).

Em termos metodológicos, os enunciados extraídos das imagens capturadas são referenciados como $E$. As respostas retiradas da seção Dúvidas, postadas no portal do MEC, são referenciadas como: $R 1$ e $R 2$, respectivamente. Por outro lado, a Justificativa 18 é referenciada como $J 18$.

Presume-se que o posicionamento assumido pelo enunciador, cujo eco se faz ouvir através do vídeo, materializado ora pela voz do narrador ora pela voz dos sujeitospersonagens do material, intenta veicular a ideia de que a MP representa algo extremamente relevante e apreciável pela sociedade civil em geral.

Vejamos: 


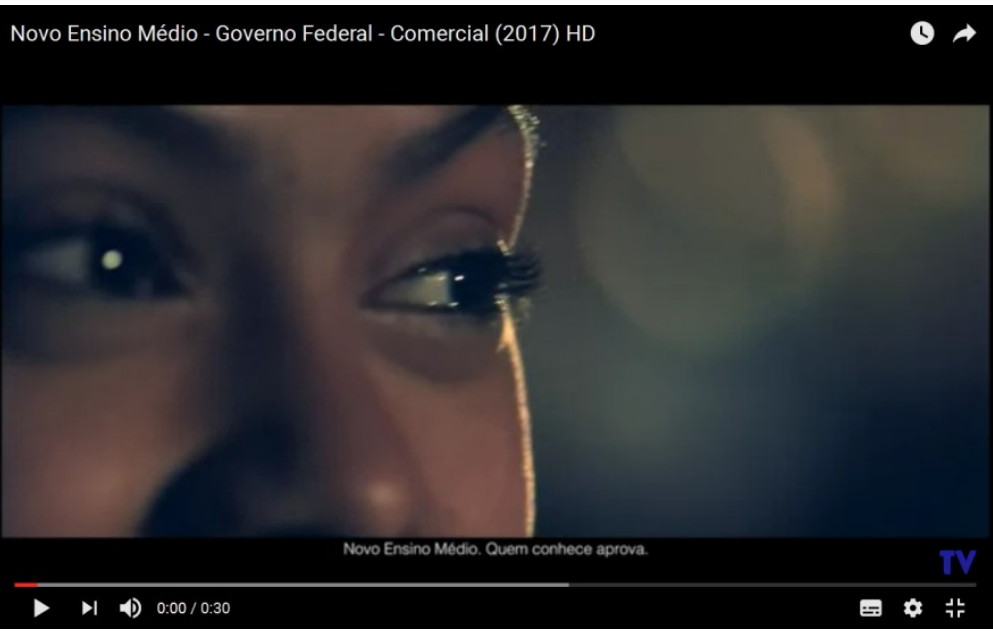

Figura 1 - Propaganda governamental do "Novo" EM - captura 1

Fonte: Elaborado pelo autor - recortado do YouTube.com.

E1: Novo Ensino Médio. Quem conhece aprova.

É interessante observar o recurso utilizado no quadro que inaugura o material audiovisual, em que os efeitos de edição operam como uma marca no plano da não neutralidade discursiva ao utilizar a técnica de close-up; afinal de contas, o discurso não é neutro. Esse procedimento, muito comum em trabalhos cinematográficos, caracterizase pelo enquadramento fechado em um único plano, no qual se prioriza uma parte de um objeto, ou assunto filmado - neste caso, o rosto de uma pessoa.

A expressividade nos olhos, transmitindo um ar de satisfação, entusiasmo, ou ainda encantamento, tende a moldar a cena, adquirindo uma significação que ultrapassa os limites da sua existência particular, tal que na imbricação com o E1 inscreve nessa enunciabilidade a naturalização do sentido de que a MP é algo indiscutível e, portanto, aceitável, com a qual todo cidadão brasileiro estaria de acordo, pois "quem conhece aprova". Apoiar, então, estaria no campo semântico da aceitação de que a MP necessita, de fato, ser implementada no âmbito do sistema educacional brasileiro, entendendo-a como uma medida (im/pro)posta que vai ao encontro das necessidades atuais do estudante de EM.

Cria-se, assim, um efeito de reflexividade na medida em que esse material tende a refletir a si mesmo como uma dimensão fiel da realidade, "pois qualquer signo ideológico é não apenas um reflexo, uma sombra da realidade, mas também uma parte material dessa realidade" (VOLÓCHINOV, 2017 [1929; 1930], p. 94).

Essa reflexividade cria um efeito ilusório de verdade, por meio da qual se pode interpretar que o sentido é esse e não outro. Assim, conquistam-se adeptos pelo suposto entendimento de que aqueles que conhecem a proposta tendem a concordar indubitavelmente com ela, visto que o uso do pronome interrogativo quem é empregado de modo genérico. Ou seja, seu referente pode ser qualquer cidadão brasileiro que se enquadre nessa formulação, reforçando, assim, a naturalização de um efeito de sentido de aprovação massiva. 
É por esse viés que se pode corroborar o dizer de Brandão (2004, p. 21) quando a estudiosa afirma que: "[a ideologia] é um instrumento de dominação de classe porque a classe dominante faz com que suas ideias passem a ser ideias de todos".

Cria-se ainda um efeito de apagamento da necessidade de se colocar em discussão uma política de fomento com tamanho impacto na sociedade. Esse silenciamento leva a significar em outro lugar (ORLANDI, 2007).

Temos, aqui, um aspecto político no ato de colocar em palavras A ao passo que se silencia B. Eis o dizer de um lugar cujo recorte implica não se calar, mas levar o indivíduo a dizer algo para não dizer outra coisa. Nessa perspectiva, trazemos ao diálogo as considerações de Orlandi (2007) acerca da política do silêncio (silenciamento):

[...] - como o sentido é sempre produzido de um lugar, a partir de uma posição do sujeito ao dizer, ele estará, necessariamente, não dizendo 'outros' sentidos. Isso produz um recorte necessário no sentido. Dizer e silenciar andam juntos [...] o silêncio recorta o dizer. Essa é uma dimensão política (ORLANDI, 2007, p. 53).

Esse aspecto político do silêncio está presente no cerne da contradição contida em todo signo ideológico, qual seja: "A classe dominante tende a atribuir ao signo ideológico um caráter eterno e superior à luta de classes, apagar ou ocultar o embate das avaliações sociais no seu interior" (VOLÓCHINOV, 2017 [1929; 1930], p. 113).

Essa dimensão é importante na medida em que ela neutraliza os sentidos, levando o destinatário a concordar com o que está posto pelo enunciador, que no caso do vídeo está incorporado pelo discurso da classe dominante (burguesia) no fluir das coerções neoliberais.

Levando em conta os fundamentos da semântica global, nesse ponto reside $o$ estatuto do enunciador e do destinatário, em que o enunciador (= a classe dominante; quem tem a propriedade privada dos meios de produção) e o destinatário (= a classe trabalhadora; a população brasileira em geral) são colocados no mesmo plano de coerção discursiva, pois "cada discurso define o estatuto que o enunciador deve se atribuir e o que deve atribuir a seu destinatário para legitimar seu dizer" (MAINGUENEAU, 2008, p. 87).

Por esse prisma é que se pode dizer "a verdade de ontem como se fosse a verdade de hoje" (VOLÓCHINOV, 2017 [1929; 1930], p. 113). Dito de outra forma, isso determina a particularidade do signo ideológico de refletir a realidade dentro das fronteiras da ideologia dominante. Ou seja, enuncia-se um pretenso novo, porém, revestido com velhos paradigmas. Assume-se, portanto, "quem conhece aprova", para não dar margem à contestação, pois ao colocar a proposta em discussão "quem conhece pode vir a reprovar".

Da seção Dúvidas, acerca da proposta do "Novo" EM, publicada no portal do MEC, retiramos a primeira resposta referente à pergunta: "O que é a reforma do EM?"

Vejamos: 
R1: A reforma do ensino médio é uma mudança na estrutura do sistema atual do ensino médio. Trata-se de um instrumento fundamental para a melhoria da educação no país. Ao propor a flexibilização da grade curricular, o novo modelo permitirá que o estudante escolha a área de conhecimento para aprofundar seus estudos. A nova estrutura terá uma parte que será comum e obrigatória a todas as escolas (Base Nacional Comum Curricular) e outra parte flexível. Com isso, o ensino médio aproximará ainda mais a escola da realidade dos estudantes à luz das novas demandas profissionais do mercado de trabalho. E, sobretudo, permitirá que cada um siga o caminho de suas vocações e sonhos, seja para seguir os estudos no nível superior, seja para entrar no mundo do trabalho.

Fonte: $\operatorname{MEC}(2016$, online).

A partir da materialidade linguística presente nessa sequência discursiva, pode-se inferir que três temas se impõem por meio da "relação semântica privilegiada com o sistema de restrições" (MAINGUENEAU, 2008, p. 84), próprios aos enunciados postos em circulação nesse funcionamento discursivo, a saber: (1) avanço; (2) escolhas; e (3) flexibilização.

De acordo com Fiorin (1998, p. 24), "tema é o elemento semântico que designa um elemento não-presente no mundo natural, mas que exerce o papel de categoria ordenadora dos fatos observáveis". Nesse campo da abstração, afirma-se que um tema imposto, podendo ser recuperado por meio do fio enunciativo, e que converge, portanto, semanticamente com o sistema de restrições,

[...] é definido não apenas pelas formas linguísticas que o constituem - palavras, formas morfológicas e sintáticas, sons, entonação -, mas também pelos aspectos extraverbais da situação. Sem esses aspectos situacionais, o enunciado torna-se incompreensível, assim como aconteceria se ele estivesse desprovido de suas palavras mais importantes (VOLÓCHINOV, 2017 [1929; 1930], p. 228).

Isso implica a mobilização de um conjunto de vocabulário particular, termos investidos de um significado que faz sentido dentro dos limites de determinado funcionamento discursivo. É possível afirmar, então, que a utilização dessas unidades semânticas incide sobre o posicionamento dos enunciadores, que são "levados a utilizar aqueles que marcam sua posição no campo discursivo” (MAINGUENEAU, 2008, p. 81).

No Quadro 1 (na página a seguir) buscamos sistematizar os principais temas observados na sequência discursiva $R 1$ :

Tem-se, assim, que a proposta do "Novo" EM opera a partir de um funcionamento discursivo interpenetrado pelos temas avanço, escolhas e flexibilização, cujos sentidos podem ser recuperados por meio de trechos do vídeo e do próprio texto da MP.

As unidades semânticas dão contorno ao enunciado, cooperando para conferir um sentido de totalidade ao fio discursivo, sendo, portanto, "parte inseparável e necessária do enunciado [...] o tema do enunciado é essencialmente indivisível" (VOLÓCHINOV, 2017 [1929; 1930], p. 229). Dessa maneira, não caberia aqui subdividir, por exemplo, a unidade semântica "permitir entrar no mundo do trabalho" em seus elementos linguísticos. Interessa-nos no processo de significação do tema o todo do enunciado. 


\begin{tabular}{|l|l|}
\hline Temas: & Unidades semânticas: \\
\hline (1) Avanço & - Reforma; \\
& - Melhoria; \\
& - Novo modelo; \\
& - Nova estrutura; \\
& - Novas demandas; \\
& - Mudança na estrutura. \\
\hline (2) Escolhas & - Permitir entrar no mundo do trabalho; \\
& - Permitir seguir os estudos no nível superior; \\
& - Permitir seguir o caminho das vocações e sonhos. \\
\hline (3) Flexibilização & - Estrutura flexível; \\
& - Aproximar a escola da realidade dos estudantes. \\
\hline
\end{tabular}

\section{Quadro 1 - Temas que atravessam o discurso do "Novo" EM}

Fonte: Elaborado pelo autor.

Acerca do tema 1 destaca-se que ele materializa discursivamente uma nova proposta, um novo EM que todos aprovam. Já com relação ao tema 3, esse discurso de flexibilização é falho na medida em que a própria LDBEN já se apresenta de modo flexível, em se tratando da organização da EB em séries anuais, períodos semestrais, levando em conta idade, competência e outros critérios. Além disso, considera-se também, no Art. $23 \S 2^{\circ}$, a possibilidade de adequação do calendário escolar às peculiaridades locais, considerando, ainda, questões climáticas e econômicas, podendo, inclusive, ocorrer a redução do número de horas letivas previsto por Lei.

Nota-se, assim, que a Lei tem sido bastante flexível, levando em conta sobremaneira as características e particularidades da mesorregião na qual as unidades escolares estão situadas, as necessidades e especificidades educativas dos estudantes, 0 formato dos cursos, garantindo certa autonomia às escolas, desde que se cumpra com a carga horária letiva prevista.

No que se refere ao texto da MP, Art. 36, podemos citar alguns trechos em que é possível presumir que essa pretensa flexibilização é posta em circulação; vejamos:

$\S \mathbf{1}^{\circ}$ Os sistemas de ensino poderão compor os seus currículos com base em mais de uma área prevista nos incisos I a V do caput.

$\S 3^{\circ}$ A organização das áreas de que trata o caput e das respectivas competências, habilidades e expectativas de aprendizagem, definidas na Base Nacional Comum Curricular, será feita de acordo com critérios estabelecidos em cada sistema de ensino.

$\S \mathbf{1 5}^{\circ}$ Além das formas de organização previstas no art. 23, o ensino médio poderá ser organizado em módulos e adotar o sistema de créditos ou disciplinas com terminalidade específica, observada a Base Nacional Comum Curricular, a fim de estimular o prosseguimento dos estudos.

Observa-se que $\S 1^{\circ}, \S 3^{\circ}$ e $\S 15^{\circ}$ não apresentam grande novidade tendo em vista que a LDBEN já garante bastante flexibilidade aos sistemas de ensino, como já foi 
mencionado. No entanto, essa flexibilidade é colocada à prova quando se leva em consideração que a obrigatoriedade dos estudos no "Novo" EM, ancorada na Base Nacional Comum Curricular (BNCC), é prover os estudantes na base da Lei, unicamente, com a oferta do ensino de língua portuguesa e matemática.

Fica permitido aos sistemas de ensino, entretanto, compor seus currículos com base em mais de uma área prevista nos Incisos I a V, quais sejam: I - linguagens; II matemática; III - ciências da natureza; IV - ciências humanas; V - formação técnica e profissional. Isso requer dizer, por exemplo, que nas situações em que há carência de professor de algum componente curricular que faz parte da área IV, o que tende a não ser absurdo algum tendo em vista o quadro de escassez de mão de obra no setor de ensino público, a unidade de ensino não tem a obrigatoriedade de ofertar esse itinerário formativo.

Já o parágrafo $\S 10^{\circ}$ prescreve que o estudante poderá cursar outro itinerário formativo das áreas de conhecimento propostas ao final do EM, na forma subsequente. No entanto, essa é uma questão bastante discutível, pois dependendo das condições, o estudante já se dará por satisfeito de ter terminado o estágio final da $\mathrm{EB}$, entendendo que não será necessário aprimorar sua visão de mundo a partir do aprofundamento de estudos em outra área do conhecimento que deveria ser parte integrante de sua formação humana.

Em outra direção, afirma-se ainda que os estudantes de áreas periféricas que não têm condições de migrar para as escolas privadas, caso eles queiram estudar filosofia, ou tenha aptidão para as artes, os esportes, terão que se conformar caso sua escola não oferte estas disciplinas. Ou seja, eles não terão escolha. Entretanto, imagina-se que a escola privada continuará, por certo, a ofertar todos os itinerários formativos, mas ela tende a permanecer destinada a uma pequena parcela da população brasileira.

No que tange, mais especificamente, ao tema escolhas, observemos as imagens seguintes:

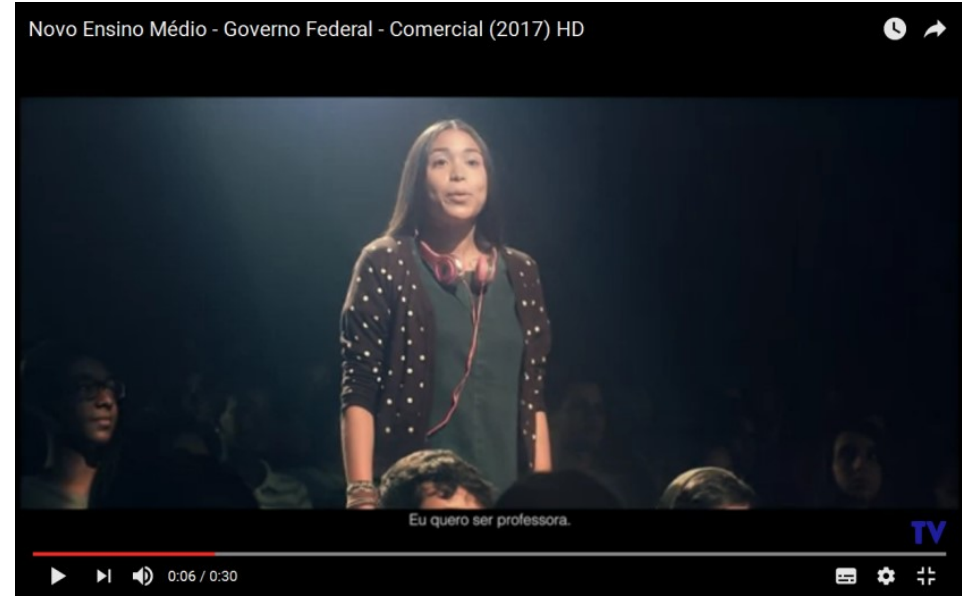

Figura 2 - Propaganda governamental do "Novo" EM - captura 2

Fonte: Elaborado pelo autor - recortado do YouTube.com.

E2: Eu quero ser professora. 


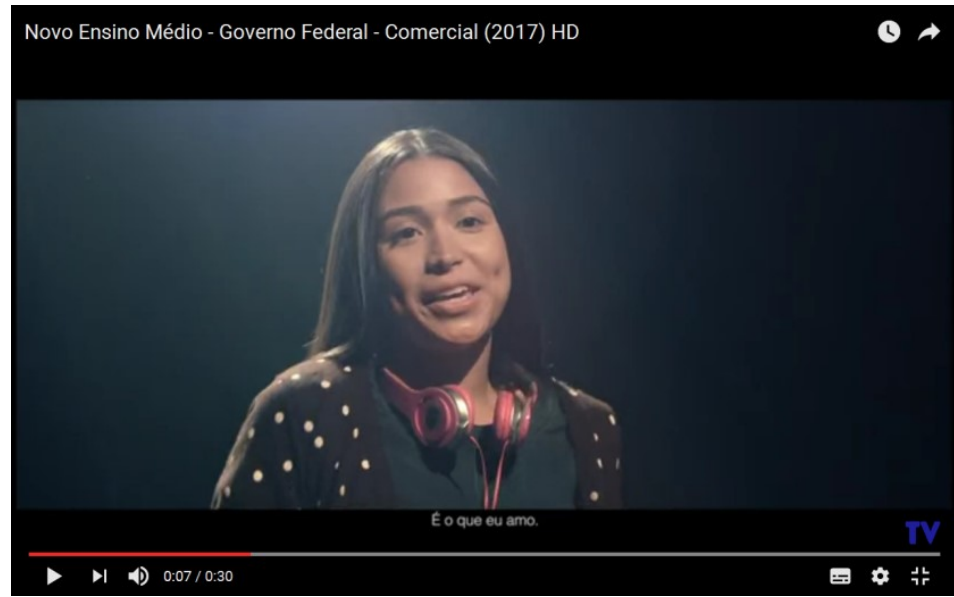

Figura 3 - Propaganda governamental do "Novo" EM - captura 3

Fonte: Elaborado pelo autor - recortado do YouTube.com.

E3: É o que eu amo.

Ao assistir ao vídeo, nota-se um sentimento de realização incorporado no dizer dos sujeitos-personagens (figuras 2-3) que assumem um posicionamento de liberdade diante da possibilidade de optar por um caminho a seguir em sua formação. A expressividade conferida à interpretação, por meio da impostação apropriada da voz, do gestual investido, e da própria expressão facial, busca imprimir um tom de satisfação por poder fazer suas próprias escolhas, desejo tão comum aos jovens, referenciados comumente como sendo o futuro de uma nação.

No entanto, essa encenação ideológica acaba por criar um efeito de apagamento do fato de que, em qualquer idade, mas, sobretudo na adolescência, fazer escolhas não é algo fácil - principalmente diante das múltiplas possibilidades que o mundo nos oferece e da própria "adolescência como uma etapa do desenvolvimento humano que se caracteriza por apresentar alterações físicas, emocionais e sociais advindas de uma nova visão de mundo que passa a rodear o jovem" (MOTTA, 2016, p. 41), influenciando sobremaneira nessa tomada de decisão.

Além disso, cabe destacar que:

\begin{abstract}
A sociedade moderna tornou-se um lugar inóspito para a escolha profissional. A grande mobilidade das funções, ou a vida muito curta de funções devido ao desenvolvimento tecnológico, aliado às crises que acompanham a juventude tem dificultado muito o ato específico de se escolher uma profissão numa sociedade em constante movimento (MOTTA, 2016, p. 39).
\end{abstract}

Em sua pesquisa, ao analisar a escolha profissional do adolescente, Motta evidencia a dificuldade de escolher caminhos, principalmente por conta dos diferentes fatores psicológicos envolvidos neste processo. É um momento cercado de muita pressão, pois o que está em jogo muitas vezes é o cumprimento de "um rito de passagem, ou seja, ao ter escolhido uma profissão, o jovem ultrapassa a barreira para se tornar adulto" (MOTTA, 2016, p. 40). 
Nesse aspecto, pode-se afirmar que os enunciados E2 (Eu quero ser professora.) e E3 (É o que eu amo.) estão em sintonia com o discurso da MP como uma medida que visa permitir aos jovens estudantes fazer escolhas, porém, essa é uma condição que não depende simplesmente de sua vontade.

Não é o "Novo" EM que lhes permite alcançar esse objetivo, visto que o aprofundamento dos estudos em nível superior, ao concluir a EB, é previsto em Lei, e corroborado por diversos documentos normativos da educação brasileira. Tem-se com esse deslizamento de sentido um efeito ilusório de que a MP permitirá ao jovem ter maior liberdade com as escolhas.

O que não é verdade, principalmente quando se toca na questão do ensino de língua estrangeira (LE), tão relevante para a formação integral dos estudantes, visto que ela amplia a percepção do indivíduo como ser humano e cidadão, promovendo conexões com um olhar diferenciado sobre o mundo, em um constante contraponto com a rica cultura brasileira.

Sabe-se, porém, que caberá ao sistema de ensino prover os estudantes, obrigatoriamente, com a oferta de inglês, podendo ofertar outras línguas em caráter optativo. Conhecendo a realidade da maioria das escolas públicas brasileiras, acreditamos que isso acarretará uma grande perda, pois muitas escolas tenderão a priorizar, única e exclusivamente, o ensino desse componente curricular em detrimento de outros idiomas, como se pode depreender pela resposta à pergunta 2 - "E a língua inglesa? Por que foi escolhida como obrigatória?" -, postada no portal do MEC:

R2: Anteriormente, a LDB não trazia a língua inglesa como estudo obrigatório. A reforma torna o inglês obrigatório desde o $6^{\circ}$ ano do ensino fundamental e no ensino médio. Os sistemas de ensino poderão ofertar outras línguas estrangeiras se assim desejarem, preferencialmente o espanhol. A língua inglesa é a mais disseminada e a mais ensinada no mundo inteiro.

Fonte: $\operatorname{MEC}(2016$, online).

Ao propagar a ideia de que "a LDB não trazia a língua inglesa como estudo obrigatório", esse enunciado se alinha ao discurso naturalizado de que o inglês é o idioma mais importante e, por isso, merece destaque, devendo tornar-se, portanto, obrigatório. No entanto, sabe-se que o inglês tem sido a primeira opção de escolha das redes de ensino público ao longo de décadas, por questões econômicas e geopolíticas históricas.

A ideologia dominante do mundo capitalista neoliberal, que atravessa essa enunciação, tem feito eco ao discurso de que é preciso aprender inglês, o que, no Brasil, acabou culminando com a expansão de cursos livres de idiomas em diversas partes do país.

A MP representa, assim, um retrocesso no que diz respeito ao que foi conquistado com a Lei 11.161/2005, que previa que o ensino de espanhol deveria se dar como oferta obrigatória pela escola e de matrícula facultativa para o estudante, sendo implantado, gradativamente, nos currículos plenos do EM.

Em face dessa questão, afirmamos que a MP busca silenciar o papel desempenhado por essa LE, negligenciando a sua relevância para os aprendizes falantes de espanhol no Brasil, país circundado por diferentes nações onde o idioma é falado na América do Sul 
- um idioma com cerca de quinhentos milhões de falantes, sendo considerado, depois do mandarim, o segundo idioma mais falado no mundo por número de usuários da língua, e o segundo idioma de comunicação internacional na comunidade global, atrás do inglês.

Partindo para o próximo quadro capturado, evidencia-se mais detidamente um aspecto crucial: a formação de jovens para o mercado de trabalho em lugar do foco na formação integral. Consideramos que há uma filiação da MP a esse discurso de preparação de massa de trabalho acrítico, como, inclusive, se depreende por meio dos enunciados presentes na R1.

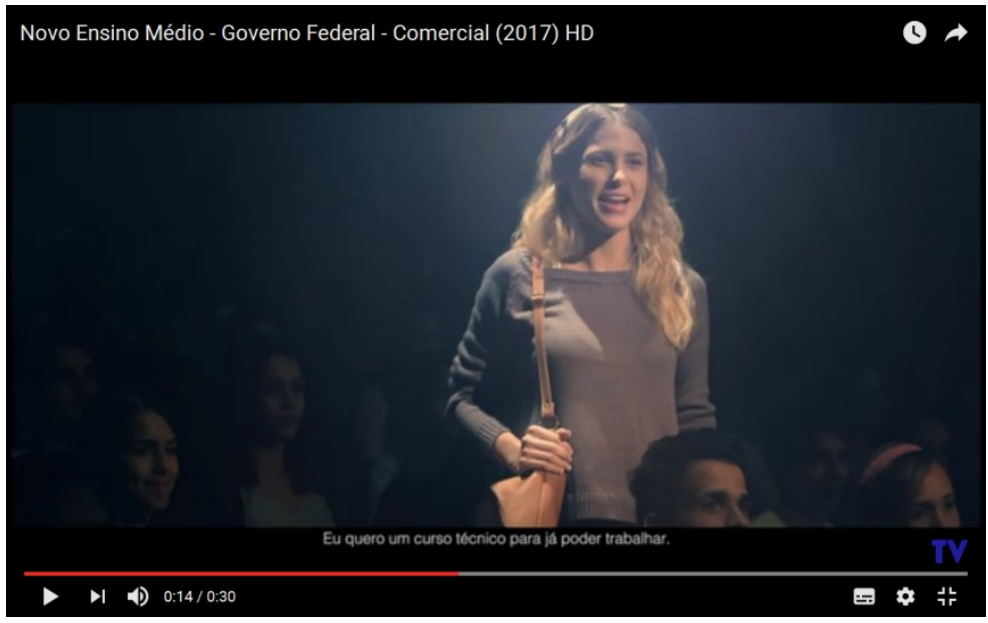

\section{Figura 4 - Propaganda governamental do "Novo" EM - captura 4}

Fonte: Elaborado pelo autor - recortado do YouTube.com.

E4: Eu quero um curso técnico para já poder trabalhar.

Infere-se por meio do E4 que o que está em jogo, aqui, é a preparação para o mercado de trabalho, como demanda do capital, reforçado também pela Justificativa 18, enviada pelo Governo Federal ao Congresso Nacional, cujo propósito é salientar seu potencial em atender às orientações do Banco Mundial de reduzir os gastos públicos, o que implicaria a abertura para a privatização de sistemas públicos de ensino:

J18: Um novo modelo de ensino médio oferecerá, além das opções de aprofundamento nas áreas do conhecimento, cursos de qualificação, estágio e ensino técnico profissional de acordo com as disponibilidades de cada sistema de ensino, o que alinha as premissas da presente proposta às recomendações do Banco Mundial e do Fundo das Nações para Infância - Unicef.

Fonte: CAMARA DOS DEPUTADOS - Legislação (2016).

Finalmente, as imagens que seguem ajudam a realçar ainda mais o discurso da possibilidade de escolhas, colocando em circulação enunciados que se filiam à unidade semântica "permitir seguir o caminho das vocações", fazendo ecoar a liberdade para tomar decisões, refletindo-se mutuamente, pois "os enunciados não são indiferentes entre si nem se bastam cada um a si mesmos; uns conhecem os outros e se refletem mutuamente uns nos outros" (BAKHTIN, 2016 [1895-1975], p. 57). 

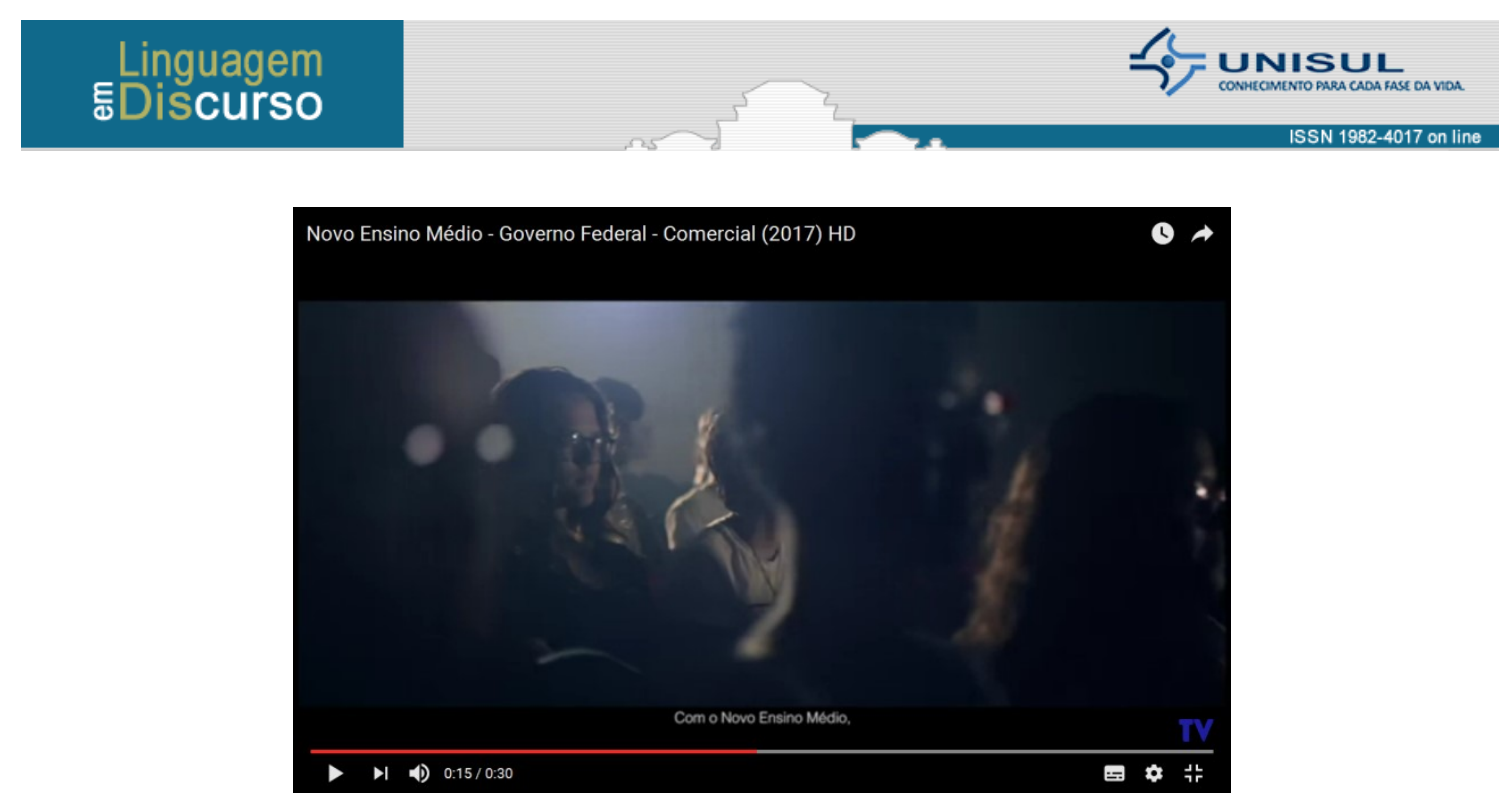

Figura 5 - Propaganda governamental do "Novo" EM - captura 5

Fonte: Elaborado pelo autor - recortado do YouTube.com.

E5: Com o Novo Ensino Médio,

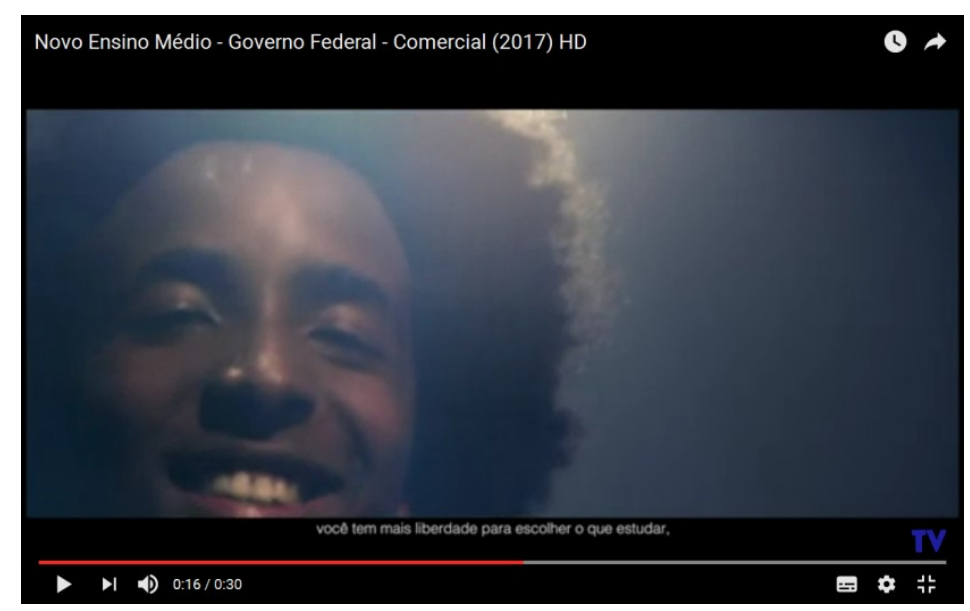

Figura 6 - Propaganda governamental do "Novo" EM - captura 6

Fonte: Elaborado pelo autor - recortado do YouTube.com.

E6: você tem mais liberdade para escolher o que estudar,

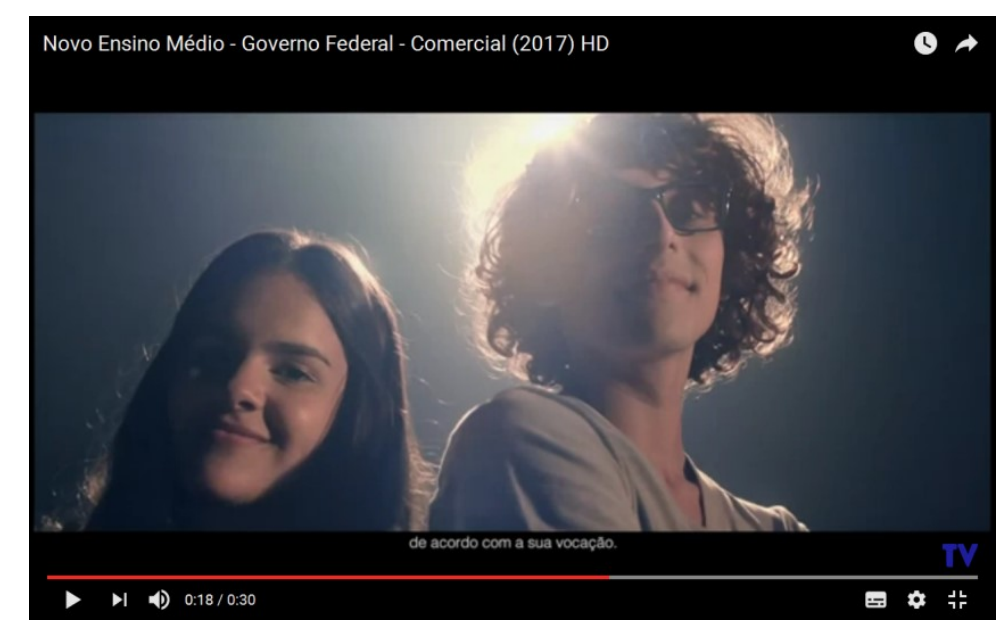

Figura 7 - Propaganda governamental do "Novo" EM - captura 7

Fonte: Elaborado pelo autor - recortado do YouTube.com.

E7: de acordo com a sua vocação. 
Este texto objetivou apresentar uma análise da materialidade linguística presente em sete quadros, recortados de um material audiovisual, televisionado, de propaganda do "Novo" EM. O vídeo em questão foi tomado como material ideológico sígnico, tal que o marco teórico utilizado abarcou a sociologia do discurso do Círculo de Bakhtin em diálogo com a $\mathrm{AD}$ de base enunciativa, sob o enfoque da semântica global.

Além disso, ao investigar a deriva de sentidos postos em circulação por meio de enunciados sobre trabalho e formação integral a partir das sequências discursivas recortadas para análise, focalizamos o texto da MP, duas respostas postadas na seção Dúvidas, no portal do MEC, além da Justificativa 18 retirada do texto que o Governo Federal enviou ao Congresso Nacional, como forma de defender a necessidade de se implementar essa proposta no âmbito da educação brasileira.

Pode-se dizer que, nessa interdiscursividade, observou-se a imposição de três temas pertinentes, atravessando o fio enunciativo, convergindo, portanto, semanticamente com o sistema de restrições nesse funcionamento discursivo, quais sejam: avanço, flexibilização e escolhas.

Esses temas mobilizam unidades semânticas que cooperam para o deslizamento de sentidos, refletindo a ideologia dominante, a qual se encontra filiada ao discurso capitalista neoliberal, cuja natureza implica a subordinação à relação entre o capital e o trabalho. Essa construção ideológica visa sempre ao lucro, o que, em outras palavras, significa fomentar a transformação da mão de obra em massa de trabalho, colocando os trabalhadores a serviço dos detentores das propriedades privadas dos meios de produção.

Ademais, na tentativa de abarcar a totalidade da nação brasileira, criando um efeito ilusório de verdade de que a MP é do agrado de todos, parte-se da utilização de sujeitospersonagens na figura de jovens que ambicionam a possibilidade de ter liberdade para fazer suas escolhas. Porém, não se contempla o caráter plural e multiétnico da sociedade brasileira.

Nesse sentido, a propaganda do governo é falha, pois apresenta as posições-sujeito de jovens brancos e negros, mas se exclui os povos originários, negligenciando o fato de que o nosso país é miscigenado, o resultado da mistura de etnias e nacionalidades, cujo pilar de sustentação é formado, historicamente, pelas populações de matrizes indígenas, por povos de matrizes africanas e pelo branco europeu.

Silenciar a necessidade de se fomentar também a formação integral das populações indígenas, levando em conta as suas particularidades e as demandas locais, é dar voz ao discurso da exclusão, cooperando, assim, para a manutenção do crime contra esses povos, alvos de ataques constantes e massacres que têm assolado e dizimado suas comunidades em nosso país.

Afirmamos também que a deriva de sentidos postos em circulação por meio do vídeo evidenciou o silenciamento do trabalho como princípio ontológico, em sua dimensão educativa, reduzindo-o ao mero papel de reprodutor de práticas de empregabilidade. Nesse sentido, por conseguinte, faz-se ouvir o ressoar de vozes que apagam os sentidos da formação do indivíduo em sua plenitude, integral, enquanto formação para a vida e para o mundo do trabalho, como um cidadão consciente do seu papel político e social, dando eco, contudo, à preparação para o mercado. 
Nesse sentido, o que se tem é um retrocesso com a MP, em lugar de um avanço, na medida em que o que se pretende é colocar no mercado profissionais acríticos, com formação limitada, com o intuito apenas de atender às demandas do sistema capitalista (neoliberal) de produção. Dessa forma, não se coopera para a construção de uma sociedade mais justa, com mais equidade e menos desigualdades, formando cidadãos brasileiros integrados à sociedade de modo reflexivo, crítico e, sobretudo, cônscios de seu papel transformador.

\section{REFERÊNCIAS}

BAKHTIN, M. Os gêneros do discurso. São Paulo: Editora 34, 2016 (1895-1975).

BAUMAN, Z. Modernidade líquida. Rio de Janeiro: Zahar, 2001.

BEZERRA, D. S. Ensino médio (des)integrado: história, fundamentos, políticas e planejamento curricular. Natal, RN: Editora do IFRN, 2013.

BRANDÃO, H. H. N. Introdução à análise do discurso. Campinas, SP: Editora da Unicamp, 2004.

BRASIL. Ministério de Educação e Cultura. Lei n. 9.394, de 20 de dezembro de 1996. Estabelece as Diretrizes e Bases da Educação Nacional. Brasília: MEC, 1996.

BRASIL. Ministério da Educação. Secretaria de Educação Média e Tecnológica. Parâmetros Curriculares Nacionais (Ensino Médio). Brasília: MEC, 2000.

BRASIL. Orientações Curriculares para o Ensino Médio. Linguagens, códigos e suas tecnologias / Secretaria de Educação Básica. Brasília: Ministério da Educação, Secretaria de Educação Básica, 2006.

BRASIL. Medida Provisória $n^{\circ} 746$, de 22 de setembro de 2016. Institui a Política de Fomento à Implementação de Escolas de Ensino Médio em Tempo Integral, e dá outras providências. Diário Oficial da União, Brasília, DF, p. 1-2, 23 set. 2016. Seção 1.

BUENO, D. G. M. Institutos Federais de Educação, Ciência e Tecnologia: uma política a ser cravada na história. Curitiba: Appris, 2015.

CÂMARA DOS DEPUTADOS. Legislação informatizada-Medida Provisória $N^{\circ} 746$, de 22 de setembro de 2016 - Exposição de motivos. EM nº 00084/2016/MEC. Brasília, 15 de setembro de 2016. Disponível em: https://www2.camara.leg.br/legin/fed/medpro/2016/medidaprovisoria-746-22-setembro2016-783654-exposicaodemotivos-151127-pe.html. Acesso em: 20 abr. 2017.

CIAVATTA, M. A formação integrada: a escola e o trabalho como lugares de memória e identidade. In: FRIGOTTO, G.; CIAVATTA, M.; RAMOS, M. (Orgs.). Ensino médio integrado: concepção e contradições. São Paulo: Cortez, 2012, p. 83-106.

FIORIN, J. L. Linguagem e ideologia. São Paulo: Editora Ática, 1998.

FRIGOTTO, G. Concepções e mudanças no mundo do trabalho e o ensino médio. In: FRIGOTTO, G.; CIAVATTA, M.; RAMOS, M. (Org.). Ensino médio integrado: concepção e contradições. São Paulo: Cortez, 2012, p. 57-82.

MACHADO, M. R. L.; MOREIRA, P. R. Educação profissional no Brasil, evasão escolar e transição para o mundo do trabalho. In: Seminário Nacional de Educação Profissional e Tecnológica (SENEPT), 2012, Belo Horizonte. Anais do Seminário. Belo Horizonte: Centro Federal de Educação Tecnológica de Minas Gerais (CEFET-MG), 2012. Disponível em:

http://www.senept.cefetmg.br/galerias/Arquivos_senept/anais/terca_tema3/TerxaTema3Poster9.pdf. Acesso em: 20 abr. 2017.

MAINGUENEAU, D. Gênese dos discursos. São Paulo: Parábola Editorial, 2008.

MARX, K. O capital: crítica da economia política. Rio de Janeiro: Civilização Brasileira, 2016 (1890).

MEC. Ministério da Educação. Novo Ensino Médio - Dúvidas. 2016. Disponível em:

http://portal.mec.gov.br/component/content/article?id=40361\#nem_07. Acesso em: 20 abr. 2017.

MOTTA, P. T. R. O aluno mudou e eu nem percebi: ensino técnico, mercado de trabalho e estudo de perfis.

ORLANDI, E. P. As formas do silêncio: no movimento dos sentidos. Campinas, SP: Editora da Unicamp, 2007. 
OUTHWAITE, W.; BOTTOMORE, T. Dicionário do pensamento social do século XX. Rio de Janeiro: Zahar, 1996.

PACHECO, E. Institutos Federais: uma revolução na educação profissional e tecnológica. São Paulo: Moderna, 2011.

SILVA, W. F. Evasão escolar nos cursos técnicos integrados do IFBA campus Eunápolis. $25^{\circ}$ Simpósio Brasileiro e $2^{\circ}$ Congresso Ibero-Americano de Política e Administração da Educação. $C D-R O M$ do Simpósio com os trabalhos completos. ANPAE, p. 1-14, 2011. Disponível em: http://www.anpae.org.br/simposio2011/index.htm. Acesso em: 20 abr. 2017.

SILVEIRA, Z. S. Contradições entre capital e trabalho: concepções de educação tecnológica na reforma do ensino médio e técnico. Jundiaí: Paco Editorial, 2010.

TERSAC, G.; MAGGI, B. O trabalho e a abordagem ergonômica. In: DANIELLOU, F. (Org.). $A$ ergonomia em busca de seus princípios: debates epistemológicos. São Paulo: Edgar Blücher, 2004, p. 79-104. VOLÓCHINOV, V. Marxismo e filosofia da linguagem: problemas fundamentais do método sociológico. São Paulo: Editora 34, 2017 (1929-1930).

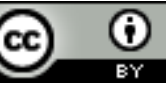

Este texto está licenciado com uma Licença Creative Commons Atribuição 4.0 Internacional. 